\title{
UJI AKTIVITAS ANTIJAMUR BEBERAPA SENYAWA MONOKARBONIL ANALOG CURCUMIN HASIL SINTESIS
}

\section{Antifungal Activity of Some Synthesized Mono-Carbonyl Analogue Compounds of Curcumin}

\author{
Ismi Rahmawati*, Desi Purwaningsih \\ Fakultas Farmasi, Universitas Setia Budi, JI Letjend Sutoyo, Surakarta 57127 \\ *Email: ismirahmawati@setiabudi.ac.id
}

\begin{abstract}
Fungal resistance can pose a threat to future fungal infections, therefore studies to find other compounds that have antifungal activity need to be done. The aim of this study was to examine antifungal activity of synthesized curcumin analogue compounds i.e. 2,6-Bis-(2'-furilidin)cyclohexanone (26FuH); 2,5-Bis-(2'-furilidine)-cyclopentanone (25FuP) and 1,5-Difuril-1,4pentadien-3-on (15FuA). The curcumin analogue compound was successfully synthesized with Aldol condensation using $\mathrm{KOH} 7.5 \%$ as the catalyst. The compound was purified and characterized by melting point, thin layer chromatography, gas chromatography with mass spectrometry, FTIR spectrophotometry, spectrophotometry $1 \mathrm{H}-\mathrm{NMR}$. The results showed pure compounds and have a structure that corresponds to the target compounds. All compound were assayed as antifungal against Candida albicans, Pityrosporum ovale, Aspergillus niger, and Trichophyton mentagrophytes. The activity of each compound represented by inhibitory diameter was analyzed by one-way ANOVA followed by post hoc Tukey $(p<0.05)$. All three compounds showed antifungal activity against Candida albicans, Pityrosporum ovale, and Aspergillus niger. The best antifungal activity was shown by $26 \mathrm{FuH}$ against Pityrosporum ovale.
\end{abstract}

Keywords: antifungal activity, curcumin, monocarbonyl, Pityrosporum ovale, synthesis

\begin{abstract}
ABSTRAK
Resistensi jamur dapat menjadi ancaman pada kasus infeksi jamur di masa mendatang, oleh sebab itu penelitian untuk menemukan senyawa lain yang memiliki aktivitas antijamur perlu dilakukan. Penelitian ini bertujuan untuk menguji aktivitas antijamur senyawa analog curcumin hasil sintesis yaitu senyawa 2,6-Bis-(2'-furilidin)-sikloheksanon (26FuH); 2,5-Bis-(2'-furilidin)siklopentanon (25FuP) dan 1,5-Difuril-1,4-pentadien-3-on (15FuA). Senyawa analog curcumin

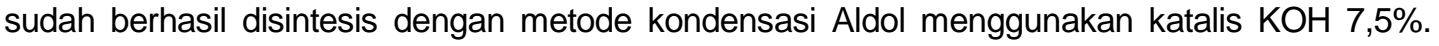
Senyawa hasil sintesis dimurnikan dan dikarakterisasi dengan menggunakan pemeriksaan organoleptis, titik lebur, kromatografi lapis tipis, kromatografi gas dengan spektrometri massa, spektrofotometri FTIR, spektrofotometri ${ }^{1} \mathrm{H}$-NMR. Hasil menunjukkan senyawa murni dan struktur sesuai senyawa target. Hasil sintesis diuji aktivitas antijamur terhadap Candida albicans, Pityrosporum ovale, Aspergillus niger dan Trichophyton mentagrophytes. Hasil diameter daya hambat dianalisis dengan ANOVA satu arah dilanjutkan post hoc Tukey $(\mathrm{p}<0,05)$. Ketiga senyawa memiliki aktivitas antijamur terhadap jamur Candida albicans, Pityrosporum ovale, dan Aspergillus niger. Aktivitas antijamur terbaik adalah senyawa 26FuH terhadap jamur Pityrosporum ovale.
\end{abstract}

Kata Kunci: aktivitas antijamur, curcumin, monokarbonil, Pityrosporum ovale, sintesis 


\section{PENDAHULUAN}

Profil Kesehatan Indonesia 2010 yang menunjukkan bahwa penyakit kulit dan jaringan subkutan menjadi peringkat ketiga dari 10 penyakit terbanyak pada pasien rawat jalan di rumah sakit se-Indonesia (Kemenkes 2012). Penyakit jamur pada kulit merupakan salah satu penyakit dengan angka prevalensi tinggi pada daerah yang beriklim tropis dan memiliki kelembaban tinggi (Jawetz et al. 2016).

Meluasnya infeksi jamur dan sedikitnya pilihan terapi yang tersedia menyebabkan resistensi antijamur menjadi masalah serius di masa yang akan datang (Apsari dan Adiguna 2013). Penelitian pola sensitivitas selama tahun 2010-2011 menunjukkan Candida albicans resisten terhadap flukonazol dan itrakonazol sebesar masingmasing $1,29 \%$ dan $4,31 \%$ di Laboratorium Mikologi Departemen Parasitologi FKUI (Yugo dan Ridhawati 2013). Pola Kepekaan Candida $s p$. terhadap berbagai antijamur di Laboratorium Mikrobiologi Fakultas

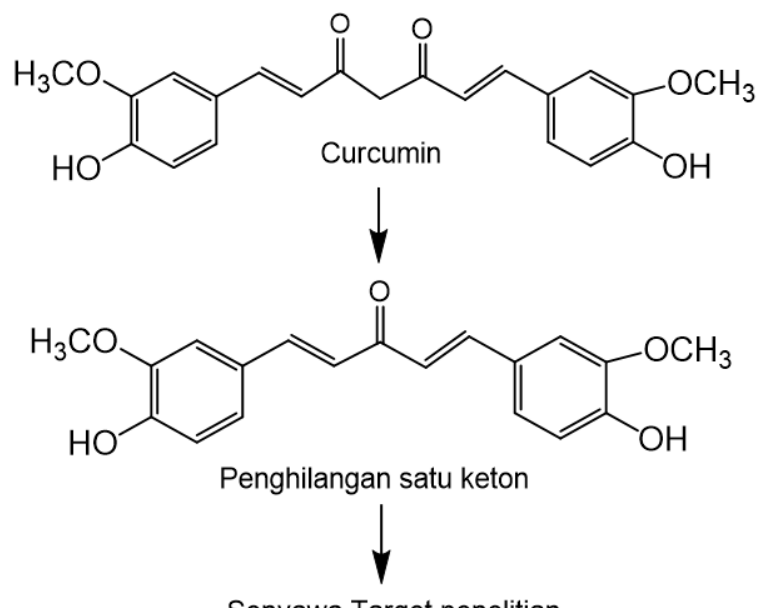
Senyawa Target penelitian<smiles>O=C1/C(=C/c2ccco2)CCC/C1=C\c1ccco1</smiles><smiles>O=C1/C(=C/c2ccco2)CC/C1=C\c1ccco1</smiles><smiles>O=C(/C=C/c1ccco1)/C=C/c1ccco1</smiles>

Gambar 1. Rencana sintesis senyawa target
Kedokteran UGM tahun 2013 juga menunjukkan resistensi terhadap beberapa antijamur walaupun sensitivitasnya masih tinggi (Nirwati dkk. 2014). Pengujian kepekaan griseofulvin, ketokonasol, itrakonasol, dan terbinafin terhadap spesies dermatofit di URJ Kesehatan Kulit dan Kelamin RSUD Dr. Soetomo Surabaya dalam Bulan Oktober sampai dengan Desember 2014 menunjukkan adanya kemungkinan resistensi terhadap spesies jamur dermatofit (Anggarini dkk. 2015).

Peningkatan resistensi antijamur dimasa depan mendorong peneliti mencari antijamur baru. Pengembangan obat baru dapat dilakukan dengan sintesis senyawa atas dasar struktur senyawa alam yang mempunyai nilai terapeutik. Senyawa alam yang memiliki aktivitas antijamur adalah curcumin dari tanaman Curcuma longa L. (Zingiberaceae) (Martins et al. 2008; Moghadamtousi et al. 2014; Khalil et al. 2012). Kelemahan kurkumin ketidakstabilan kimia, rentan terhadap degradasi pada UV dan paparan cahaya tampak (Heger et al. 2014). Kelemahan kurkumin dapat diatasi dengan memodifikasi struktur senyawa. Senyawa hasil sintesis modifikasi kurkumin yang memiliki aktivitas antijamur adalah senyawa monokarbonil analog curcumin (Sardjiman, 2000).

Senyawa analog curcumin dengan modifikasi struktur memiliki aktivitas sebagai antijamur terhadap Candida spp yang resisten flukonazol (Zhao et al. 2017). Beberapa analog curcumin yang lain yang juga berhasil di sintesis dan memiliki berbagai macam aktivitas yaitu bis-(arylmethylidene) cycloalkanones (Braga et al. 2014); 1,5-bis(2bromophenyl) penta-1,4-dien-3-one (Xiao et al. 2010) dan 1,5-diaryl-3-oxo-1,4pentadienes (Kudo et al. 2011); seri monokarbonil analog curcumin memiliki aktivitas antiproliferatif dan antiinflamasi (Katsori et al. 2011).

Analog monokarbonil curcumin dibandingkan dengan curcumin memiliki stabilitas dan profil farmakokinetik yg lebih baik (Liang et al. 2009). Rahmawati (2009) berhasil memodifikasi cincin samping dengan furfural yaitu senyawa 2,6-Bis-(2'-furilidin)sikloheksanon (26FuH); 2,5-Bis-(2'-furilidin)siklopentanon (25FuP) dan 1,5-Difuril-1,4pentadien-3-on (15FuA). Diagram struktur senyawa tersebut dapat dilihat pada Gambar 1. 
Ketiga senyawa sebelumnya diteliti memiliki aktivitas antibakteri terhadap bakteri Salmonella thypii ATCC 13311 dan Stapylococcus aureus ATCC 25923 (Rahmawati 2009). Berdasarkan aktivitas antijamur curcumin, maka penelitian ini bertujuan untuk menguji aktivitas antijamur senyawa analog curcumin hasil sintesis yaitu senyawa 2,6-Bis-(2'-furilidin)-sikloheksanon (26FuH); 2,5-Bis-(2'-furilidin)-siklopentanon (25FuP) dan 1,5-Difuril-1,4-pentadien-3-on (15FuA) terhadap jamur Candida albicans, Pityrosporum ovale, Aspergillus niger dan Trichophyton mentagrophytes.

\section{BAHAN DAN METODE}

\section{Bahan}

Bahan yang digunakan untuk sintesis ini adalah: sikloheksanon pa Merck, aseton pa Merck, furfural pa Merck, $\mathrm{KOH}$ pa Merck, etanol $96 \%$ pa Merck, diklormetan pa Merck, heksan, kloroform, silika gel GF 254, $\mathrm{HCl}$ 0,5 $\mathrm{N}$, aquades. Medium Sabround Glukosa Agar (SGA), medium Sabround Glukosa Cair (SGC), jamur Candida albicans ATCC 10231, Pityrosporum ovale ATCC 3175, Aspergillus niger ATCC 16404 dan Trichophyton mentagrophytes ATCC 18191, aquades steril, larutan standar Mc Farlan 0,5; Lactofenol Cotton Blue (LCB), Glukosa Broth, Laktosa Broth, Sukrosa Broth dan Maltosa Broth, etanol.

Peralatan yang digunakan untuk sintesis ini adalah labu alas bulat, Erlenmeyer pyrex, beker glass pyrex, pipet ukur, labu takar, corong Büchner, corong biasa, kertas saring, motor pengaduk magnetic thermolyne cimarec $\AA$, pengaduk magnetic, flakon, batang pengaduk, pipet tetes, oven pengering Memmert, Petri disk, timbangan elektrik adventurer Tm, statif, kaca arloji, alat uji titik lebur (Stuart scientific melting point apparatus SMP3), peralatan uji KLT, lampu UV 254 nm, Spektrometer FTS 3000 MX DIGILAB®, Spektrometer ${ }^{1} \mathrm{H}$ RMI JEOL-MY 60, Spektrometer GC-MS, cawan petri, tabung reaksi, disk kosong, spuit, ose, kapas lidi steril, Laminar Air Flow (LAF)

\section{Sintesis senyawa 26FuH, 25FuP dan 15FuA}

Sesuai metode sintesis Rahmawati (2009), starting material furfural $(0,01 \mathrm{mmol})$ dicampur dengan katalisator $\mathrm{KOH} 7,5 \%(0,01$ $\mathrm{mmol}$ ) dalam Erlenmeyer, diaduk dengan kecepatan 700 rpm selama 10 menit. Sambil tetap diaduk, diteteskan keton starting material yang sesuai $0,01 \mathrm{mmol}$ selama 15 menit, dilanjutkan pengadukan selama 2,5 jam. Percobaan ini dilakukan pada suhu kamar. Hasil sintesis dipindahkan ke dalam gelas beker, dinetralkan dengan $\mathrm{HCl} 0,5 \mathrm{~N}$, kemudian dilakukan pembentukan padatan dengan ditambah aquades dingin sampai 200 $\mathrm{mL}$ dan ditempatkan dalam es batu lalu didiamkan selama 20 menit. Padatan yang terbentuk disaring dalam corong Büchner dengan bantuan penyaring vakum. Padatan yang diperoleh dikeringkan. Padatan selanjutnya direkristalisasi dengan di-refluk dengan etanol absolut 10 kalinya kemudian dipanaskan. Hasil disaring dan dimasukkan dalam gelas beker dan ditempatkan dalam baskom berisi es, didiamkan selama beberapa menit. Kristal yang didapat disaring dengan corong Büchner dengan bantuan penyaring vakum, kemudian dikeringkan, ditimbang dan dihitung rendemennya.

\section{Karakterisasi ketiga senyawa}

Hasil sintesis dikarakterisasi melalui metode pemeriksaan organoleptis, penentuan titik lebur yang diukur dengan alat Electrothermal Melting Apparatus, pemeriksaan kromatografi lapis tipis, penentuan GC-MS dengan analisis MS, penentuan spektrum FTIR, dan pnentuan spektrum ${ }^{1} \mathrm{H}-\mathrm{NMR}$

Pemeriksaan kromatografi lapis tipis dengan fase gerak dengan heksana:kloroform, fase diam Silika GF 254. Pengembangan sekali elusi dengan penampakan bercak dilihat pada UV $254 \mathrm{~nm}$, UV $366 \mathrm{~nm}$.

Penentuan GC-MS dengan analisis MS dilakukan pada Shimadzu QP-500. Gas Chromatography dirangkai dengan spektrometer massa Shimadzu dengan fase diam Cpsil-5 CB (semi polar) fused silica column ( $30 \mathrm{~m} \times$ $0,25 \mathrm{~mm}$, tebal film $0,33 \mu \mathrm{m})$. Kolom terprogram suhu dari $200-300^{\circ} \mathrm{C}$ dengan kenaikan suhu $10^{\circ} \mathrm{C} /$ menit, suhu injektor $300^{\circ} \mathrm{C}$, helium sebagai pembawa pada aliran kecepatan $30 \mathrm{~mL} /$ menit. Jenis pengionan Electron Impact (EI) $70 \mathrm{eV}$, suhu injektor $300^{\circ} \mathrm{C}$.

Dalam penentuan spektrum FTIR, zat uji sebanyak $5 \mathrm{mg}$ dan $\mathrm{KBr}$ yang telah dikeringkan sebanyak $100 \mathrm{mg}$ dikempa menjadi pelet tipis yang transparan kemudian dimasukkan wadah sampel pada alat spektrofotometer infra merah, dibuat serapan pada panjang gelombang $4000-400 \mathrm{~cm}^{-1}$. 
Tabel 1. Rendemen senyawa hasil target

\begin{tabular}{lcc}
\hline Senyawa & $\begin{array}{c}\text { Total hasil } \\
\text { senyawa }(\mathrm{g})\end{array}$ & $\begin{array}{c}\text { Rendemen } \\
(\%)\end{array}$ \\
\hline $26 \mathrm{FuH}$ & 11,33 & $73,6 \pm 0,16$ \\
$25 \mathrm{FuP}$ & 11,37 & $78,6 \pm 0,25$ \\
15FuA & 19,99 & $86,0 \pm 0,14$ \\
\hline
\end{tabular}

Untuk penentuan spektrum ${ }^{1} \mathrm{H}-\mathrm{NMR}$, zat uji dibebas-airkan dahulu sebelum ditentukan dan disimpan dalam eksikator selama 2 minggu. Alat yang digunakan adalah spektrometer ${ }^{1} \mathrm{H}-\mathrm{NMR} 500 \mathrm{MHz}$, pelarut yang digunakan adalah $\mathrm{CD}-\mathrm{Cl}_{3}$.

Pembuatan suspensi dan identifikasi jamur uji Beberapa ose biakan jamur uji dalam medium Sabround Glukosa Agar (SGA) dimasukkan ke dalam tabung reaksi yang berisi $10 \mathrm{~mL}$ larutan garam fisiologis, dicampur hingga homogen. Kekeruhan suspensi biakan dibuat setara dengan standar Mc Farland 0,5. Jamur uji diidentifikasi dengan pewarnaan dengan lactofenol cotton blue, pengamatan koloni pada medium SGA dan uji pada media indikasi Glukosa Broth, Laktosa Broth, Sukrosa Broth dan Maltosa Broth.

\section{Pengujian aktivitas antijamur}

Pengujian aktivitas antijamur dilakukan dalam Laminar Air Flow (LAF) menggunakan metode difusi (CLSI 2012). Pembuatan medium SGA disterilkan. Medium SGA dituang ke cawan petri diameter $15 \mathrm{~cm}$ secara aseptis. Medium SGA yang sudah padat, dilakukan penanaman suspensi biakan jamur uji secara perataan. Hasil didiamkan 5 menit. Senyawa uji dengan konsentrasi 500 ppm dan diteteskan pada cakram kosong ukuran 8 mm sebanyak $30 \mu \mathrm{L}$. Letakkan cakram pada media dengan jarak tertentu. Cawan petri diinkubasi pada suhu $37^{\circ} \mathrm{C}$ selama $1 \times 24$ jam untuk $C$. albicans dan $P$. ovale. Inkubasi untuk $A$. niger dan $T$. mentagrophytes pada suhu $27-30^{\circ} \mathrm{C}$ (suhu kamar) selama 5 hari. Pengamatan dilakukan dengan mengukur diameter zona jernih di sekitar cakram masing-masing senyawa uji.

\section{Pengamatan dan analisa hasil}

Aktivitas antijamur ditunjukkan oleh adanya daerah jernih di sekeliling cakram kertas yang tidak ditumbuhi jamur uji. Diameter daya hambat pertumbuhan diukur dari masing-masing sampel uji, lalu diuji dengan statistik. Uji normalitas menggunakan uji satu sampel Kolmogorov-Smirnov, setelah data menunjukkan terdistribusi normal selanjutnya uji ANOVA satu arah dengan menggunakan uji lanjut Post Hoc Test model Tukey dengan nilai signifikasi 0,05.

\section{HASIL DAN PEMBAHASAN}

Penelitian ini dimaksudkan untuk mensintesis ulang senyawa 26FuH, 25FuP dan 15FuA berdasarkan mekanisme reaksi kondensasi Aldol, sikloheksanon (senyawa 26FuH), siklopentanon (25FuP), dan aseton (15FuA) berkondensasi dengan 2furfuraldehyde menggunakan katalis $\mathrm{KOH}$ $7,5 \%$ pada temperatur kamar selama 3 jam reaksi melalui proses pendiaman selama 1 jam dalam suhu kamar. Hasil sintesis seperti pada Tabel 1, total senyawa berasal dari 3 kali sintesis untuk masing-masing senyawa. Hasil karakterisasi dan elusidasi struktur senyawa 26FuH, 25FuP dan 15FuA ditampilkan pada Tabel 2 dan Gambar 2.

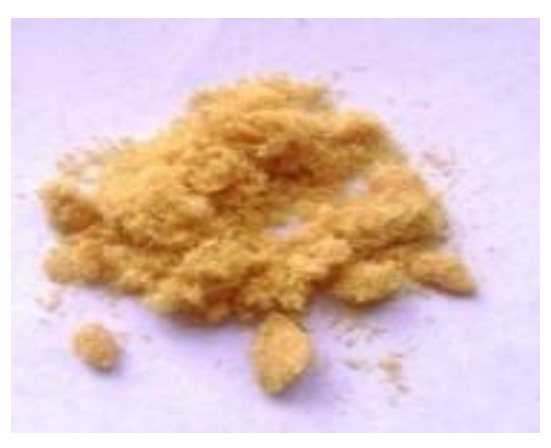

Senyawa $26 \mathrm{FuH}$

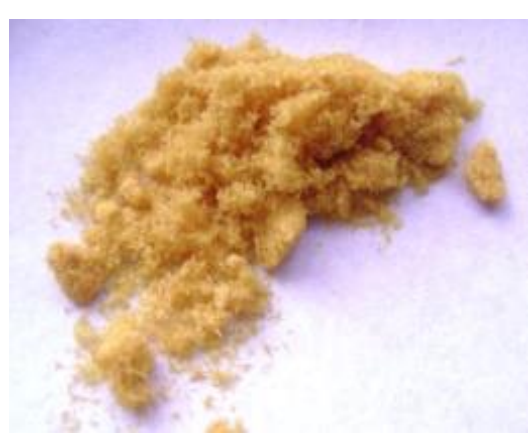

Senyawa 25FuP

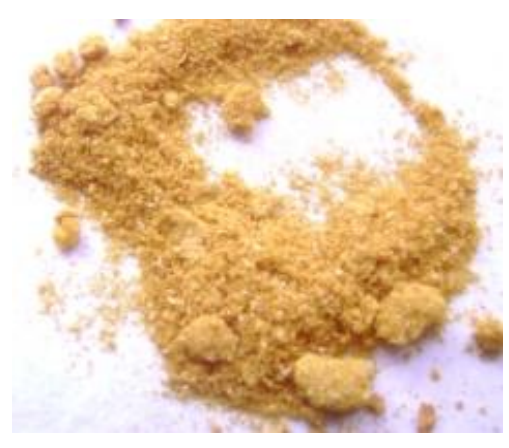

Senyawa $15 \mathrm{FuA}$

Gambar 2. Hasil sintesis senyawa target 
Tabel 2. Hasil karakterisasi dan elusidasi struktur senyawa 26FuH, 25FuP dan 15FuA

\begin{tabular}{|c|c|c|c|}
\hline \multirow{2}{*}{ Struktur } & \multicolumn{3}{|c|}{ Senyawa } \\
\hline & $26 \mathrm{FuH}$ & 25FuP & $15 \mathrm{FuA}$ \\
\hline Organoleptis & Kristal jarum, kuning oranye & Kristal jarum, kuning & $\begin{array}{l}\text { Serbuk, kuning coklat } \\
\text { gelap }\end{array}$ \\
\hline Jarak Lebur & $143,7-145,6=1,9^{\circ} \mathrm{C}$ & $163,7-164,9=1,2^{\circ} \mathrm{C}$ & $71,2-74,0=2,8^{\circ} \mathrm{C}$ \\
\hline KLT & $\begin{array}{c}\text { Silika gel } 60 \text { GF } 254 \text { Satu } \\
\text { bercak, } \mathrm{Rf}=0,33 \text { eluen= } \\
\text { heksan: } \mathrm{CHCl}_{3}=1: 2\end{array}$ & $\begin{array}{c}\text { Silika gel } 60 \text { GF } 254 \text { Satu } \\
\text { bercak, } \mathrm{Rf}=0,18 \text { eluen }= \\
\text { heksan: } \mathrm{CHCl}_{3}=1: 2\end{array}$ & $\begin{array}{c}\text { Silika gel } 60 \text { GF } 254 \text { Satu } \\
\text { bercak, } \mathrm{Rf}=0,54 \text { eluen }= \\
\text { heksan: } \mathrm{CHCl}_{3}=1: 3\end{array}$ \\
\hline GC-MS & $\begin{array}{c}\text { Luas area } 100 \%, \operatorname{tr}=22,658 \\
\text { menit, } \mathrm{m} / \mathrm{z}=254\end{array}$ & $\begin{array}{c}\text { Luas area } 100 \%, \operatorname{tr}=23,185 \\
\text { menit, } \mathrm{m} / \mathrm{z} 240\end{array}$ & $\begin{array}{c}\text { Luas area total } 93.28 \%, \\
\operatorname{tr}=28,45 ; 28,50 ; 28,56 \\
\text { dan } 28,63 \text { menit, } m / z 214\end{array}$ \\
\hline $\begin{array}{l}\text { FTIR } \\
\text { Spektrofotometri }\end{array}$ & $\begin{array}{c}\mathrm{C}-\mathrm{H}\left(2923.56 \mathrm{~cm}^{-1}\right), \\
\mathrm{C}-\mathrm{H}\left(2850.27 \mathrm{~cm}^{-1}\right), \\
\mathrm{C}=\mathrm{C}\left(1589.06 \mathrm{~cm}^{-1} \text { dan }\right. \\
\left.1465.63 \mathrm{~cm}^{-1}\right), \\
\mathrm{C}-\mathrm{O}\left(1284.36 \mathrm{~cm}^{-1}\right), \\
\text { Keton heksanon }\left(1751.05 \mathrm{~cm}^{-1}\right) \\
\text { Para substitusi }\left(817.67 \mathrm{~cm}^{-1}\right)\end{array}$ & $\begin{array}{c}\mathrm{C}-\mathrm{H}\left(2919.7 \mathrm{~cm}^{-1}\right), \\
\mathrm{C}-\mathrm{H}\left(2850.27 \mathrm{~cm}^{-1}\right), \\
\mathrm{C}=\mathrm{C}\left(1608.34 \mathrm{~cm}^{-1} \mathrm{dan}\right. \\
\left.1465.63 \mathrm{~cm}^{-1}\right), \\
\mathrm{C}-\mathrm{O}\left(1265.07 \mathrm{~cm}^{-1}\right), \\
\text { Keton pentanon }\left(1751.05 \mathrm{~cm}^{-1}\right) \\
\text { Para substitusi }\left(821.527 \mathrm{~cm}^{-1}\right)\end{array}$ & $\begin{array}{c}\text { C-H }\left(2923.56 \mathrm{~cm}^{-1}\right), \\
\text { C-H }\left(2854.13 \mathrm{~cm}^{-1}\right), \\
\mathrm{C}=\mathrm{C}\left(1623.77 \mathrm{~cm}^{-1} \mathrm{dan}\right. \\
\left.1469.49 \mathrm{~cm}^{-1}\right) \\
\text { C-O }\left(1261.22 \mathrm{~cm}^{-1}\right), \\
\text { Keton }\left(1739.48 \mathrm{~cm}^{-1}\right), \\
\text { Para substitusi }(821.527 \\
\left.\mathrm{cm}^{-1}\right)\end{array}$ \\
\hline $\begin{array}{l}\text { Spektrofotometri } \\
{ }^{1} \mathrm{H}-\mathrm{NMR}\end{array}$ & $\begin{array}{c}\delta ; p p m ~ s, 3.8549 ; d, 7,5449- \\
\text { 7,5412; d 6,6514-6,6453; q } \\
6,5035-6,4999-6,4974-6,4937 \\
\text { t, 3,0029-2,9919-2,9822; q } \\
1,8943-1,8809-1,8687-1,8565\end{array}$ & $\begin{array}{c}\delta ; p p m ~ d, ~ 7,5767-7,5742 ; s \\
7,3334 ; \text { d 6,6807-66746; q, } \\
6,5280-6,5243-6,519-6,5182 ; \mathrm{s} \\
3,0555\end{array}$ & $\begin{array}{c}\text {; ppm d, 7,5110-7,508; } \\
\text { d, 7,4914-7,4609; d } \\
6,9268-6,8950 ; \text { d 6,6896- } \\
6,6823 ; \text { t, 6,4977-6,4941- } \\
6,4904\end{array}$ \\
\hline
\end{tabular}

Tabel 3. Uji aktivitas antijamur ketiga senyawa hasil sintesis

\begin{tabular}{lcccc}
\hline \multirow{2}{*}{ Senyawa } & \multicolumn{4}{c}{ Diameter daya hambat $(\mathrm{mm})$} \\
\cline { 2 - 5 } & C. albicans & P. ovale & A. niger & T.mentagrophytes \\
\hline 26FuH & $15,7 \pm 2,1$ & $26,7 \pm 1,5$ & $17 \pm 1,0$ & $10 \pm 1,0$ \\
25FuP & $17,7 \pm 1,5$ & $23,3 \pm 1,5$ & $15,3 \pm 1,5$ & $14,3 \pm 0,6$ \\
15FuA & $17,3 \pm 0,6$ & $21 \pm 1,7$ & $16,7 \pm 0,6$ & $7,7 \pm 0,6$ \\
K (+) Nistatin & $18,3 \pm 0,5$ & $14 \pm 1,0$ & $18 \pm 1,0$ & $27,7 \pm 0,6$ \\
K (-) DMSO (1\%) & $0 \pm 0$ & $0 \pm 0$ & $0 \pm 0$ & $0 \pm 0$ \\
\hline
\end{tabular}

Senyawa 15FuA memiliki luas area di kromatografi gas sebesar $93,28 \%$ dengan muncul di 4 waktu retensi, yaitu: 28,45; 28,50 ; 28,56 dan 28,63 menit. Ke empat waktu tersebut ditunjukkan spektrofotometri massa memiliki $\mathrm{m} / \mathrm{z}$ yang sama yaitu 214 . Hal ini dapat disimpulkan hasil sintesis senyawa 15FuA memiliki 4 konfigurasi ruang yang berbeda.

Berdasarkan hasil pemeriksaan kemurnian dan elusidasi struktur dapat disimpulkan senyawa hasil sintesis memiliki karakteristik sesuai struktur senyawa target. Hasil sintesis selanjutnya diuji aktivitas antijamur.

\section{Hasil pengujian antijamur secara difusi} Sintetis tiga senyawa analog kurkumin yang telah diperoleh, selanjutnya dilakukan pengujian terhadap jamur $C$. albicans, $P$. ovale, $A$. niger dan $T$. mentagrophytes dengan metode difusi dapat dilihat pada Tabel 3 dan Gambar 3. Penentuan aktivitas antijamur dilakukan dengan metode difusi. Pengamatan dengan mengukur diameter zona hambat yang ditandai zona jernih yang muncul di sekitar cakram. Semakin luas zona hambat yang terbentuk menunjukkan bahwa semakin efektif zat tersebut sebagai zat antijamur.

Berdasarkan hasil data menunjukkan semua sampel memiliki zona hambat. Hal tersebut menunjukkan bahwa ketiga senyawa memiliki aktivitas antijamur. Berdasarkan 
Tabel 4. Hubungan Log $P$ dengan aktivitas antijamur terhadap jamur $P$. ovale

\begin{tabular}{cccc}
\hline No. & Senyawa & Log $P$ & $\begin{array}{c}\text { Diameter daya } \\
\text { hambat }(\mathrm{mm})\end{array}$ \\
\hline 1. & $26 \mathrm{FuH}$ & 1,87 & $26,67 \pm 1,53$ \\
2. & $25 \mathrm{FuP}$ & 1,45 & $23,33 \pm 1,53$ \\
3. & $15 \mathrm{FuA}$ & 1,25 & $21,00 \pm 1,73$ \\
\hline
\end{tabular}

data yang diperoleh kemudian dilakukan analisis statistik. Hasil analisis statistik dengan uji satu sampel KolmogorovSmirnov menunjukkan data terdistribusi normal. Analisis selanjutnya dilakukan uji homogenitas dengan Levene's Test of Equality of Error Variances, hasil menunjukkan data homogen, selanjutnya dilakukan ANOVA satu arah dengan menggunakan uji lanjut Post Hoc Test model Tukey dengan nilai signifikasi 0,05.

Hasil analisis statistik menunjukkan semua senyawa memiliki aktivitas antijamur yang menyamai kontrol positif kecuali pada jamur T. mentagrophytes. Hasil aktivitas pada $T$. mentagrophytes menunjukkan bahwa semua senyawa aktivitas antijamur yang lebih rendah dibandingkan kontrol positif. Hasil keseluruhan uji menunjukkan senyawa $26 \mathrm{FuH}$ memiliki aktivitas terbaik terhadap jamur uji $P$. ovale dibandingkan jamur uji yang lain.

Senyawa yang mempunyai kecenderungan lipofilik mempunyai aktivitas antijamur yang lebih baik (Thomas 2003; Podunavac-Kuzmanović dan Cvetković (2011). Sebagian besar membran jamur mengandung ergosterol. Ergosterol adalah komponen penting yang menjaga integritas membran sel jamur dengan cara mengatur fluiditas dan keseimbangan dinding membran sel jamur. Manusia tidak mensintesis ergosterol tetapi menggunakan kolesterol sebagai sterol selaput utama. Hal ini menguntungkan bila ada antijamur yang bekerja dengan berikatan pada ergosterol yang akan membuat antijamur memiliki kerja yang selektif. Salah satu mekanisme kerja obat antijamur dengan menghambat sintesis ergosterol dimana obat ini mengikat secara langsung ergosterol dan channel ion di membran sel jamur, hal ini menyebabkan gangguan permeabilitas berupa kebocoran ion kalium dan menyebabkan kematian sel. Pembentukan komplek-komplek dengan

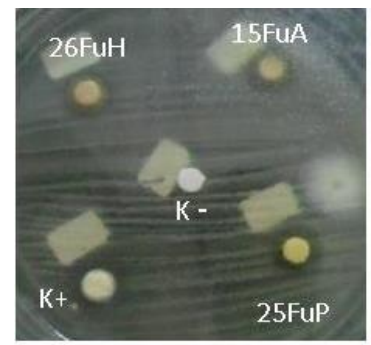

C. albicans

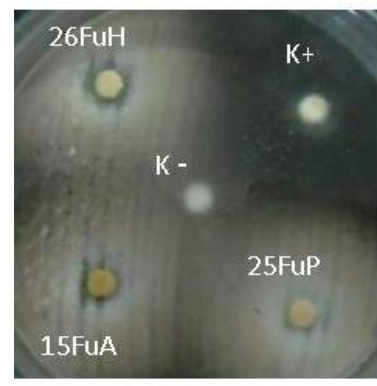

A. niger

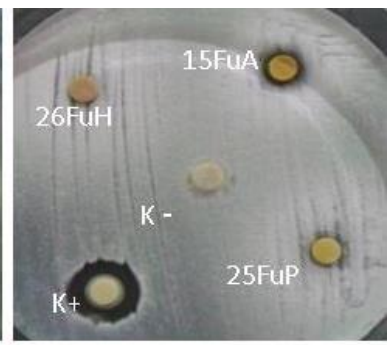

P. ovale

T. mentagrophytes

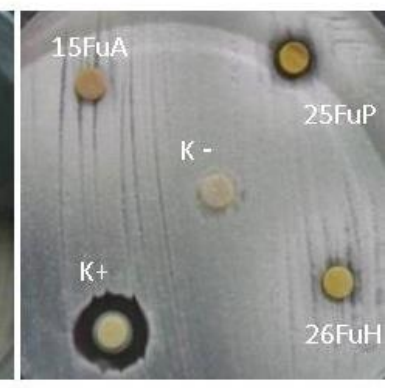

Gambar 3. Uji aktivitas antijamur dengan metode difusi $\left(\mathrm{K}_{+}=\right.$Nistatin, $\mathrm{K}-=$ DMSO 1\%)

ergosterol dalam membran sel fungi sehingga dapat menyebabkan kerusakan dan kebocoran membran (Jawetz et al. 2016).

Sifat lipofilik suatu senyawa bisa diperhitungkan dengan Chemdraw ultra versi 10 . Hasil perhitungan log $P$ dari ketiga senyawa menunjukkan senyawa $26 \mathrm{FuH}$ memiliki nilai yang tertinggi. Senyawa 26FuH merupakan senyawa dengan kecenderungan berada pada fase non polar paling tinggi, sedangkan senyawa $15 \mathrm{FuA}$ merupakan senyawa dengan kecenderungan berada pada fase non polar yang paling rendah. Senyawa yang mempunyai log $P$ yang tinggi dimungkinkan memiliki afinitas yang tinggi berada pada lapisan ergosterol di dinding $P$. ovale sehingga akan mempunyai aktivitas antijamur yang lebih baik. Perbandingan log $P$ senyawa target sintesis dan aktivitas dapat dilihat pada Tabel 4 .

\section{KESIMPULAN}

Hasil pada penelitian yang telah dilakukan menunjukkan bahwa ketiga senyawa hasil sintesis memberikan aktivitas antijamur terhadap jamur uji $C$. albicans, $P$. ovale dan $A$. niger. Senyawa 2,6-Bis-(2'furilidin)-sikloheksanon memiliki aktivitas terbaik untuk jamur $P$. ovale. 


\section{UCAPAN TERIMA KASIH}

Terima kasih pada Yayasan Pendidikan Setia Budi yang sudah memberikan hibah penelitian dasar dengan Nomor: 10/LPPM/USB/PD/XII/2017.

\section{DAFTAR PUSTAKA}

Anggarini DR, Sukanto $\mathrm{H}$, Astari L, Endraswari PD (2015) Uji kepekaan griseofulvin, ketokonasol, itrakonasol, dan terbinafin terhadap spesies dermatofit dengan metode mikrodilusi. BIKKK 27:55-62

Apsari AS, Adiguna MS (2013) Resistensi antijamur dan strategi untuk mengatasi. MDVI 40:89-95

Braga SFP, Alves EVP, Ferreira RS, Fradico JRB, Lage PS, Duarte MC, Ribeiro TG, Júnior PA, Romanha AJ, Tonini ML, Steindel M, Coelho EF, de Oliveira RB (2014) Synthesis and evaluation of the antiparasitic activity of bis(arylmethylidene) cycloalkanones. Eur $J$ Med Chem 71:282-289. doi: 10.1016/j.ejmech.2013.11.011

CLSI (2012) Methods for dilution antimicrobial susceptibility tests for bacteria that grow aerobically. Approved Standard. Ninth Edition. CLSI document M07-A9. Clinical and Laboratory, Standards Institute. Wayne, Pennsylvania USA

Heger M, van Golen RF, Broekgaarden M, Michel MC (2014) The Molecular basis for the pharmacokinetics and pharmacodynamics of curcumin and its metabolites in relation to cancers, Pharmacol Rev 66:222-307. doi: 10.1124/pr.110.004044

Jawetz E, Melnick JL, Adelberg EA (2016) Medical Microbiology, 27th Edition. McGraw-Hill Education

Katsori AM, Chatzopoulou M, Dimas K, Kontogiorgis C, Patsilinakos A, Trangas T, Hadjipavlou-Litina D (2011) Curcumin analogues as possible antiproliferative \& anti-inflammatory agents. Eur J Med Chem 46:27222735. doi:10.1016/ j.ejmech.2011.03.060

Kemenkes (2012) Profil Kesehatan Indonesia Tahun 2011. ISBN 978-602235-106-1. Kementerian Kesehatan
Republik Indonesia, Jakarta

Khalil OAK, de Faria Oliveira OMM, Vellosa JCR, de Quadros AU, Dalposso LM, Karam TK, Mainardes RM, Khalil NM (2012) Curcumin antifungal and antioxidant activities are increased in the presence of ascorbic acid. Food Chem 133:1001-1005. doi: 10.1016/ j.foodchem.2012.02.009

Kudo C, Yamakoshi $H$, Sato A, Nanjo H, Ohori $\mathrm{H}$, Ishioka $\mathrm{C}$, Iwabuchi $\mathrm{Y}$, Shibata $H$ (2011) Synthesis of 86 species of 1,5-diaryl-3-oxo-1,4pentadienes analogs of curcumin can yield a good lead in vivo. BMC Pharmacol 11:4. doi: 10.1186/14712210-11-4

Liang G, Shao L, Wang Y, Zhao C, Chu Y, Xiao J, Zhao Y, Li X, Yang S (2009) Exploration and synthesis of curcumin analogues with improved structural stability both in vitro and in vivo as cytotoxic agents. Bioorg Med Chem 17:2623-2631.

doi: 10.1016/j.bmc.2008.10.044

Martins CV, da Silva DL, Neres AT, Magalhaes TF, Watanabe GA, Modolo $L V$, Sabino AA, de Fatima $A$, de Resende MA (2008) Curcumin as a promising antifungal of clinical interest. J Antimicrob Chemother 63:337-339. doi: $10.1093 / j a c / d k n 488$

Moghadamtousi SZ, Kadir HA, Hassandarvish P, Tajik H, Abubakar S, Zandi K (2014) A Review on antibacterial, antiviral, and antifungal activity of curcumin. BioMed Research International. ID 186864. 12p. doi: $10.1155 / 2014 / 186864$

Nirwati H, Praseno, Mustofa M (2014) Isolasi Candida sp dan pola kepekaannya terhadap berbagai antijamur di Laboratorium Mikrobiologi Fakultas Kedokteran UGM. Libmed UGM pp:126-136, Yogyakarta

Podunavac-Kuzmanović SO, Cvetković DD (2011) Lipophilicity and antifungal activity of some 2-substituted benzimidazole derivatives. Chemical Industry \& Chemical Engineering Quarterly 17:9-15. doi: 10.2298/CICEQ100329044P

Rahmawati I (2009) Sintesis dan uji aktivitas antibakteri senyawa 2,6-bis-(2'Furilidin)-sikloheksanon; 2,5-bis-(2'- 
Furilidin)-siklopentanon; 1,5-difuril-1,4pentadien-3-on, Thesis, Universitas Setia Budi

Sardjiman (2000) Synthesis of some new series of curcumin analogues, antioxidative, antiinflammatory, antibacterial activities and qualitativestructure activity relationship. Thesis, Gadjah Mada University

Thomas G (2003) Fundamentals of Medicinal Chemistry. John Wiley \& Sons Ltd, West Sussex, England

Xiao J, Chu Y, Hu K, Wan J, Huang Y, Jiang C, Liang G, Li X (2010) Synthesis and biological analysis of a new curcumin analogue for enhanced anti-tumor activity in HepG 2 cells. Oncol Rep 23:1435-1441.

\subsection{2/or 00000781}

Yugo MR dan Ridhawati (2013) Pola kepekaan Candida albicans terhadap flukonazol dan itrakonazol secara in vitro: Tinjauan pada bahan klinik Laboratorium Mikologi Departemen Parasitologi FKUI Periode 2010-2011. Program Studi Pendidikan Dokter Fakultas Kedokteran, Universitas Indonesia

Zhao F, Dong HH, Wang YH, Wang TY, Yan ZH, Yan F, Zhang DZ, Cao YY, Jin YS (2017) Synthesis and synergistic antifungal effects of monoketone derivatives of curcumin against fluconazole-resistant Candida spp. Medchemcomm 8:1093-1102. doi: $10.1039 / \mathrm{c} 6 \mathrm{md} 00649 \mathrm{c}$ 